\title{
АКТИВНЫЕ ПРОЦЕССЫ В СИСТЕМЕ ОБРАЗОВАНИЯ ПРОИЗВОДНЫХ ПРЕДЛОГОВ
}

\author{
ACTIVE PROCESSES IN THE SYSTEM OF FORMING DERIVATIVE \\ PREPOSITIONS
}

\section{ALEKSANDER TSOI}

\begin{abstract}
The Russian language is constantly supplemented with derivative prepositions. Supplementing the language system with new lexical units is a continuous process. The main ways of forming derivative prepositions are transposition and diffusion.
\end{abstract}

Aleksander Tsoi, Uniwersytet Łódzki, Łódź - Polska, tsoyalex2002@gmail.com

На протяжении всей истории своего развития русский язык, унаследовав из праславянского служебные слова, которые принято называть непроизводными (первообразными), постоянно пополняется производными предлогами, которые обогащают систему служебных слов русского языка, делают ее разнообразной и гибкой, а производность как проявление асимметрии языкового знака играет важную роль в устройстве и функционировании языковой структуры.

Производные предлоги образовывались в русском языке из падежных и предложно-падежных форм существительных, которые, переходя в предлоги, приобретали признаки наречия, а уже потом становились предлогами (внутрь, кругом, поперек, сверху). Предлоги вместо, спустя, благодаря и др. образовывались от существительных и иных частей речи без этой промежуточной „наречной” ступени. Начиная с XVIII века на базе свободных предложно-падежных сочетаний слов были образованы отыменные предлоги $b$ продолжение, $b$ силу, $b$ течение, по причине, по случаю, с помощью и др. Возникли также отглагольные предлоги благодаря, включая, исключая, начиная от (c), не считая и др. ${ }^{1}$

Со временем употребление конструкций с производными предлогами привело к усложнению структуры простого предложения. Г. А. Золотова отмечает, что падежные формы с производными предлогами в отличие от падежных форм с непроизводными предлогами обычно не входят в предикативную основу предложения, а включа-

1 Д.Н. Ш м е л е в, К вопросу о „производных" служебных частях речи и междометиях, [в:] его же, Избранные труды по русскому языку, Москва 2002, с. 336-349. 
ются в предложение в качестве варианта выражения отношений между знаменательными словами.

Например, трансформация предложения Петров критикует Сидорова с включением производного предлога со стороны в предложение Критика со стороны Петрова $b$ адрес Сидорова требует дальнейшего распространения в виде следующих вариантов: Критика со стороны Петрова $b$ адрес Сидорова оказалась ошибочной; или Критика со стороны Петрова в адрес Сидорова была голословной и т. д. В предложениях Петров критикует Сидорова и Критика со стороны Петрова $b$ адрес Сидорова оказалась ошибочной моделируется действие между субъектом и его объектом - адресатом; и то и другое предложение - простое, но включение в первое производного предлога потребовало его дальнейшего смыслового распространения" 2 .

Таким образом, включение производного предлога со стороны в простое предложение расширяет его и влечет необходимость распространения смысла, дополнительной информации.

Принято считать, что причиной появления производных предлогов является интенсивное совершенствование системы служебных средств связи между словами, вызванное недостаточным количеством служебных слов для передачи в языке разнообразных отношений, возникающих в объективной действительности.

Типологические особенности современного русского литературного языка характеризуют его как язык синтетико-аналитического типа. Замена синтетического способа управления аналитическим в значительной степени осуществляется непроизводными (первообразными) предлогами, которые, дополняя значение падежа, дают возможность более точно и ясно передать тот или иной оттенок мысли. Появляющиеся при этом новые предложные конструкции отражают усиление аналитических тенденций в развитии синтаксического строя русского литературного языка.

Е. А. Земская пишет следующее:

Рост аналитизма обнаруживается также в активизации конструкций с предлогами, вытесняющих конструкции без предлогов. Приведу лишь несколько примеров: изменение расписания $\rightarrow$ изменения $b$ расписании, ссора соседей $\rightarrow$ ссора между соседями, подарок сестре $\rightarrow$ подарок для сестры, ему свойственно $\rightarrow$ для него свойственно. Особенно активен предлог по, обозначающий сферу деятельности: позищия по Чечне, план по трубам, конференизи nо Кавказуз

2 Г. А. 3 о л о т о в а, Предлог „со стороны”, „Русская речь” 1969, № 1, с. 52-54.

3 Е. А. З е м с к а я, Активные процессы в русском языке последнего десятилетия ХХ ве$\kappa a$, часть 3, [в:] электронный ресурс: http://linguistics-online.narod.ru/index/0-396 (18.09.2015). 
Существенна роль в развитии этого процесса производных предлогов, которые сформировались в русском языке в результате транспозиции слов из различных частей речи в этот класс служебных слов. В первую очередь это относится к предлогам типа вдали от, незадолго до, исходя из, по направлению $к$ и др. При изучении истоков появления производных предлогов учеными было установлено, что они образовывались по разным причинам. В одних случаях была потребность в точных грамматических средствах выражения отношений между полнозначными словами, в других - в уточнении самих многозначных непроизводных предлогов, не справляющихся со своими грамматическими функциями выражения определенных отношений.

Переходя в разряд предлогов, отдельные формы полнозначных слов утрачивают грамматические признаки соответствующей части речи и приобретают признаки, присущие служебным словам. Исходным условием перехода слов других частей речи в разряд предлогов является развитие в них релятивности, и ее значение относит предлоги к разряду неизменяемых слов, но не всякое знаменательное слово при соответствующих условиях может развить служебные свойства и перейти в разряд служебных. Служебные свойства обнаруживаются у слов, в значении которых заложен элемент релятивности, например, касаться (глагол) - касательно (предлог); относиться (глагол) - относительно (предлог) и др. В результате постоянного употребления полнозначных слов в релятивном значении происходит закрепление за словом предложной функции. Например, такова судьба существительных вид, место, отличие, причина, цель, которые выступают в роли компонентов предлогов или самих предлогов вbuдy, bместо, $b$ отличие от, по причине, в челях.

Система служебных слов русского языка постоянно развивается и пополняется, в языке активно функционирует уже сформировавшаяся группа новых производных предлогов, союзов и частиц, члены которой выполняют служебные функции связи слов в словосочетаниях и предложениях, и именно эти служебные слова не включаются в толковые словари русского языка. Еще Л. В. Щерба отмечал, что в роли предлогов очень часто выступают слова и группы слов, которые обыкновенно не фигурируют ни в грамматиках, ни в словарях в качестве предлогов (посредством чего-либо, $b$ отличие от чего-либо, по поводу чего-либо и др. $)^{4}$. Принято считать, что служебные слова как элементы языковой системы оказывают существенное влияние на другие ее элементы, которые находятся к ним в пре- и постпозиции, поскольку

4 Л. В. Щ е р б а, Преподавание языков в школе: общие вопросы методики, Москва 2003, c. 78-80. 
грамматические значения служебных слов, изменяя стоящие рядом слова, развивают в них дополнительные значения.

Рассматривая причины появления производных предлогов, необходимо выделить две главные. Во-первых, производные предлоги образуются в связи с потребностью в точных грамматических средствах выражения отношений между словами, и в момент своего появления они однозначны и грамматически целесообразны. Во-вторых, они возникают в результате развития многозначности непроизводных предлогов, которая размывает границы их грамматических значений. В результате непроизводные предлоги перестают справляться с точным выражением тех или иных грамматических отношений. Сущность перехода отдельных форм полнозначных слов в разряд предлогов состоит в том, что они утрачивают грамматические признаки соответствующей части речи и приобретают признаки, присущие предлогам. Приобретение ими новых значений и функций осуществляется с помощью непроизводных предлогов и закрепления той или иной падежной формы, например, $b$ виде, по направлению, при всем, со стороны, а иногда с помощью аффиксов и предлогов, например, вблизи от $(b+$ близи от), вдалеке от $(b+$ далеке от), вовнутрь (во + внутрь), вплотную $к(b+$ плотную $\kappa)$, накануне $($ на + кануне $)$ и др. ${ }^{5}$

В процессе выработки в знаменательном слове служебных свойств основное лексическое значение слова разрушается, что и делает возможным его употребление в служебной функции для выражения связи между словами, но в этом процессе постепенного перехода знаменательных слов в служебные в языке появляются промежуточные формы совмещения служебных свойств слова с прежними, знаменательными его свойствами.

Показателем развивающихся служебных свойств слова являются его грамматические изменения, например, предлог благодаря требует дательного падежа знаменательного слова (благодаря помощи друга), а глагол благодарить - винительного (благодаря друга за помощь). Изменение управления способствует отдалению формирующегося предлога от исходного слова, а дополнительным условием выработки служебных свойств у слова является частота его употребления в новой функции, способствующей закреплению в сознании языковой личности новой смысловой особенности слова, связанной со служебным его употреблением.

Поскольку предлоги относятся к разряду неизменяемых слов и основным их признаком является значение релятивности, то разви-

5 А. С. Ц о й, Три этапа „жизненного изикла” производных предлогов, „Филологические науки", Москва 2006, № 5, с. 81-88. 
тие этого значения у полнозначных слов становится исходным условием для процесса их „опредложивания”. Предложные значения приобретаются формами знаменательных слов в результате их регулярного использования в служебной функции ${ }^{6}$.

Проблема выделения этапов образования производных служебных слов, а также обозначение самого процесса образования производных служебных слов позволяет по-другому взглянуть на природу производных предлогов.

Первый этап образования и развития служебных слов начинается с уподобления знаменательных слов служебным. Непроизводные предлоги в составе новых производных сохраняют свою полисемию, отражающую прежде всего собственно предложные отношения. Исчерпав полностью внутренние ресурсы для точного выражения отношений, непроизводные предлоги заставляют языковую систему переводить знаменательные слова в определенной форме в разряд слов служебных с новыми моносемичными значениями.

Производные предлоги вначале появляются в письменной речи, поскольку в устной для уточнений используются невербальные средства коммуникации, кроме того, производные предлоги в живой разговорной речи почти не используются еще и потому, что являются принадлежностью главным образом книжного, официально-делового и научного стилей. Так, гипотетически исходной точкой появления, например, производных пространственных предлогов может считаться необходимость для пишущего в точном указании места объекта или субъекта в пространстве. При создании текста автором подбираются слова, которые как раз и позволяют точно указать или уточнить координаты объекта, субъекта, события и т. д. Удачно выбранное слово для передачи пространственного отношения закрепляется в качестве производного предлога.

В образовании производных предлогов прослеживаются два микроуровня. Первый микроуровень - это транспозиция, например, наречий или деепричастий, в разряд предлогов. Процесс транспозиции полнозначных слов в служебные обнаруживает сложное и разностороннее взаимодействие лексики и грамматики, при котором происходит постепенное отмирание у слова старого качества и приобретение нового.

К предлогам, образованным в результате транспозиции, относятся вокруг, около, против, рядом, благодаря, исключая, начиная и др. Эти слова характеризуются амбивалентностью, поскольку функционируют в язы-

6 Роль релятивности в процессе образования производных предлогов подробно описана в работе Е. Т. Черкасовой. См.: Е. Т. Ч е р к а с о в а, Переход полнозначных слов в предлоги, Москва 1967. 
ке, сохраняя связь с каждым из своих исходных предшественников в категориальных классах. Традиционно слова вокруг, около, против, рядом рассматриваются как предлоги, если управляют падежами, и наречия, если не управляют, а лексемы благодаря, исключая, начиная при тех же позиционных условиях выступают в предложениях как деепричастия.

Второй микроуровень в образовании производных предлогов назовем дифффузией непроизводных предлогов в составе предложно-падежных сочетаний. Непроизводные предлоги, как и падежные формы имени, входя в состав предложно-падежных сочетаний, теряют свою самостоятельность, перестают обладать своим значением и образуют новую целостную служебную единицу. Например, к предлогам, образованным в результате диффузии, относятся следующие: $b$ conровождении, в стороне от, за пределы, на базе, рядом с (со) и др.7

В связи с необходимостью определения границ предлогов, которая осложняется открытостью и активностью их образования, возникает вопрос о разграничении словоформ и словосочетаний. Решение данного вопроса важно и с теоретической точки зрения, и для изучения языковой действительности, а именно возникновения и функционирования производных предлогов.

Под диффузией подразумевается, что в процессе создания предложения непроизводный предлог, распространяясь в нем, осуществляет ряд равнонаправленных действий: во-первых, включается в словосочетание; во-вторых, взаимодействует со словом, стоящим в препозиции; в-третьих, изменяет знаменательное слово в постпозиции, уподобляя его предлогу. Иными словами, грамматика непроизводных предлогов определяет процесс соединения сем предлогов и знаменательных слов при их непосредственном контактировании друг с другом. Взаимное проникновение сем является результатом упорядоченного соединения слов с целью выражения различных отношений в соответствии с их лексической и грамматической заданностью.

Преобразование полнозначных слов, непосредственно находящихся в контакте с предлогами, в первую очередь, выражается в изменении их семантики, а следующим этапом является расширение их „опредложенности”. Такова схема создания условий для образования новой служебной единицы. А дальнейшая востребованность и частота использования опредложенных образований в письменной речи способствует их закреплению в языке в качестве предлогов.

7 А. С. Ц о й, Жизненный цикл производных предлогов, [в:] Функииональная семантика, семиотика знаковых систем и методы их изучения. 1 Новиковские чтения. Материалы Международной научной конференции. Москва 5-6 апреля 2006, Российский университет дружбы народов, Москва 2006, с. 300-304. 
Внедрение семантики предлога в знаменательные слова сродни семантическому перепрограммированию их прежнего функционирования в языке: взаимодействие знаменательного слова с предлогом (предлогами) изменяет код работы знаменательного слова, а появление категориального значения опредложенности не позволяет ему в зафиксированной форме дальше оставаться в группе знаменательных слов.

Непроизводный предлог, который стал компонентом производного предлога, соединившись со знаменательным словом, также меняет свое значение. В результате прежнее предложно-падежное единство уже с новым значением приобретает функции служебной части речи.

Так, например, М. В. Всеволодова, Е. В. Клобуков, О. В. Кукушкина и А. А Поликарпов различают морфологический предлог (типа $b, н a, u 3$, от) и синтаксический предлог (типа В порядке, на протяжении, по адресу) - функционально синтаксическую единицу, функционирующую как одно служебное средство и выполняющую ту же функцию, что и предлог. Сочетания типа задолго до осени, незадолго до войны, незадолго перед праздником представляют собой целостные предложные единицы, содержащие сему с временным ориентиром („,3а много времени / не за много времени до чего-л., перед чем-л.")8.

Таким образом, движение компонентов предложно-падежного сочетания друг к другу и выравнивание значения релятивности, установление равновесия между компонентами этого сочетания создают условия для образования в языке производного служебного слова. Переход знаменательных слов в служебные представляет собой весьма длительный процесс.

Новые производные предлоги, в свою очередь, продолжают работу по дальнейшему уподоблению своего ближайшего окружения, сохраняя способность управления своей репликацией. Так, в языке появляются вариации предлогов, „подобия предлогов”, различающиеся по количеству входящих в них элементов. При этом динамика изменений сохраняется: продолжается дальнейшее уподобление знаменательных слов предлогам с вовлечением в этот процесс все большего количества полнозначных слов ${ }^{9}$. С развитием и усложнением письменной речи

8 М. В. В с е в о л о д о в а, Е. В. Кл о б у к о в, О. В. К у к у ш к и н а, А. А. П о л и к а р п о в, К основаниям функционально-коммуникативной грамматики русского предлога, „Вестник МГУ. Сер. 9: Филология”, Москва 2003, № 2, с. 19-59.

9 Под руководством М.В. Всеволодовой группа лингвистов, работая над научным проектом „Грамматика русского предлога: выявление состава предложных единиц, их категоризация и системное описание их функционально-коммуникативных свойств”, подготовила „Реестр предложных единиц русского языка, созданный данным коллективом, включает шесть с половиной (6500) тысяч единиц". 
должно поступательно увеличиваться количество новых производных служебных слов. Например, предложно-падежные сочетания незадолго до, незадолго перед, $b$ надежде на, $b$ содружестве $c$, по имени, по фрамилии, bысотой от (до), диаметром $b, c$ точностью до позиционируются уже как находящиеся на пути к окончательному закреплению в языке в качестве производных предлогов ${ }^{10}$.

Не всякое полнозначное слово может стать элементом нового предлога. Непроизводные предлоги, как правило, взаимодействуют с теми знаменательными словами, которые более предпочтительны для связи, а именно с теми, которые: а) содержат сему, отражающую одну из следующих понятийных категорий: время, место, причина, цель, условие, качество, количество и др. ${ }^{11}$; б) могут развивать элемент релятивности; в) имеют возможность функционировать в языке в одной из грамматических форм в составе производного предлога; г) находятся в непосредственной близи к непроизводному предлогу.

Можно предположить, что если слово не отвечает одному из этих условий, то оно не сможет стать компонентом нового производного служебного слова, а диффузии с непроизводным предлогом не произойдет. Если же в качестве элемента сочетания знаменательное слово отвечает перечисленным признакам, то оно становится весьма жизнеспособным в структуре нового производного предлога.

Некоторые слова обладают большими потенциальными возможностями для образования новых предлогов. Это слова, входящие в следующие активные семантические зоны: 1) параметрическую зону (слова ширина, высота, длина, толщина, формат и др.), 2) зону с целевым значением, 3) зону пространства, 4) зону со значением состояния, 5) зону времени, 6) зону комитатива (обозначение сопровождающего действия, признака, сопутствующего предмета, соучаствующего лица, например, приказ за подписью директора) ${ }^{12}$.

Очевидно, что новый производный предлог становится необходим языковой системе и появляется только в том случае, если способен более четко выразить значение релятивности по сравнению с существу-

См.: Аннотация к отчету по результатам реализации проекта 07-06-00343, финансируемого Российским фондом фундаментальных исследований, по состоянию на 09.09.2015, [в:] электронный ресурс: http://www.rfbr.ru/rffi/portal/project_search/o -57365

10 М. В. В с е в о ло д о в а, Е. В. Кл об ук о в, О. В. Ку куш кина, А. А. Поли к а р п о в, указ. соч.

11 М. И. К о н ю ш к е в и ч, Русские и белорусские предлоги: списочный состав, закономерности образования, первый опыт составления, „Вестник МГУ. Сер. 9: Филология", Москва 2005, № 4, с. 67.

12 Там же, с. 64-79. 
ющими предлогами, а также если может подменить существующий предлог на правах элемента предложной системы как более дифференцированное и совершенное средство выражения мысли.

Итак, внутри системы служебных слов естественным образом обнаруживается специфическая закономерность: лексическая система служебных слов при невозможности дальнейшего использования непроизводных предлогов онтологически начинает формироваться за счет элементов других уровней, и новые элементы этой системы начинают функционировать вне прямой зависимости от своих предшествующих функций, опираясь на новую, вновь приобретенную систему значимостей. Таким образом, система служебных слов стремится сформировать свою систему знаков и отношений, морфологизируя лексические, словообразовательные и синтаксические единицы и отношения, что позволяет ей обслуживать ограниченным числом средств бесконечное число семантико-синтаксических пропозиций, возникающих в речи. Исследование данной проблемы в расширенном формате, как представляется, в итоге дает полное представление об эволюции служебных частей речи в русском языке. Изучение развития служебных слов позволяет утверждать, что пополнение языковой системы новыми лексическими единицами представляет собой непрерывный процесс, а наглядно представить различные пути этого пополнения позволяет дифференциация способов образования служебных слов на транспозицию и диффузию.

\section{Библиография}

В с е в о ло д о в а М. В., К л о бу ко в Е. В., Кукушки н а О. В., По лик а р п о в А.А., К основаниям функционально-коммуникативной грамматики русского предлога, „Вестник МГУ. Сер. 9: Филология”, Москва 2003, № 2, с. 19-59.

3 е м с к а я Е. А., Активные проиессы в русском языке последнего десятилетия ХХ века, часть 3, [в:] электронный ресурс: http://linguistics-online.narod.ru/index/0-396 (18.09.2015).

3 о л о т о в а Г. А., Предлог „со стороны”, „Русская речь” 1969, № 1, с. 52-54.

К о н ю ш к е в и ч М. И., Русские и белорусские предлоги: списочный состав, закономерности образования, первый опыт составления , „Вестник МГУ. Сер. 9: Филология”, Москва 2005, № 4, с. 67.

Ч е р к а с о в а Е. Т., Переход полнозначных слов в предлоги, Москва 1967.

Ц о й А. С., Жизненный цһикл производных предлогов, [в:] Функциональная семантика, семиотика знаковых систем и методы их изучения. 1 Новиковские чтения. Материалы Международной научной конференции. Москва 5-6 апреля 2006, Российский университет дружбы народов, Москва 2006, с. 300-304. 
Ц о й А. С., Три этапа „жизненного циикла" производных предлогов, „Филологические науки", Москва 2006, № 5, с. 81-88.

Щ е р б а Л. В., Преподавание языков в школе: общие вопросы методики, Москва 2003, c. $78-80$.

Ш м е л е в Д. Н., К вопросу о „производных” служебных частях речи и междометиях, [в:] его же, Избранные труды по русскому языку, Москва 2002, с. 336-349. 